\title{
Study on the Integrated Risk Radar Model in Natural Scenic Areas
}

\author{
Junxiang Zhang ${ }^{1}$, Chongfu Huang ${ }^{2,3}$, Shanfeng $\mathrm{Hu}^{1}$ \\ ${ }^{1}$ Tourism College, Huangshan University, Huangshan,245021, China \\ ${ }^{2}$ Key Laboratory of Environmental Change and Natural Disaster, Ministry of Education of China, \\ Beijing Normal University, Beijing 100875, China \\ ${ }^{3}$ Academy of Disaster Reduction and Emergency Management, Ministry of Civil Affairs \& Ministry \\ of Education, Beijing 100875, China
}

\author{
自然风景区综合风险雷达模式研究 \\ 张俊香 $^{1}$, 黄崇福 ${ }^{2,3}$, 胡善风 ${ }^{1}$ \\ ${ }^{1}$ 黄山学院旅游学院, 黄山 245021, 中国 \\ ${ }^{2}$ 北京师范大学环境演变与自然灾害教育部重点实验室, 北京 100875 , 中国 \\ ${ }^{3}$ 民政部/教育部减灾与应急管理研究院, 北京 100875 , 中国
}

\begin{abstract}
Facing the severe challenges of disaster risk management and the continuous improvement of the quality requirements of tourists in natural scenic areas, the construction of Smart Disaster Prevention in scenic areas has become a very important and urgent work. Integrated risk radar has the role of discovery, identification, monitoring and management of dynamic risk. Integrated risk radar can achieve the "wisdom" of the comprehensive disaster prevention system, and optimize the operation of the comprehensive disaster prevention system in scenic spots. This paper reviews state-of the-art relating to disaster risk and risk radar at home and abroad, puts forward the model of the integrated risk radar and discusses its application in the scenic spot. This paper aims to provide a new way of thinking for the wisdom of disaster prevention in natural scenic areas.
\end{abstract}

Key Words: risk radar; integrated risk; smart disaster prevention; natural scenic area

\section{摘要}

面对自然风景区灾害风险管理的严峻挑战和 游客对于旅游的品质要求的不断提升, 智慧防 灾景区的建设成了目前极为重要且迫切的工 作。景区综合风险雷达具有发现、识别、监测 和管理动态风险的作用, 能够实现景区综合防 灾体系的 “智慧化”, 优化提升景区综合防灾 体系的运作效果。综述了国内外景区灾害风险 与风险雷达的研究现状, 提出了景区综合风险 雷达的模式, 并探讨了其在景区的应用情景。 本研究旨在为建立智慧防灾景区, 实现景区防 灾的智慧化提供一个新的思路。

关键词: 风险雷达; 综合风险; 智慧防灾; 自 然风景区

\section{1. 引言}

旅游业对各种自然及人为灾害相当脆弱 敏感, 例如, 1999 年 9 月 21 日, 以南投县集 集镇为中心的台湾中部发生 7.3 级强烈地震, 造成财产损失约合 92 亿美元, 占当年 GDP 的 $3.3 \%$ 。其中, 旅游业受损约 48 亿元新台币, 距震中仅 9.2 公里的日月潭风景区遭受百年 大劫, 灾区民营观光业损失约 37 亿元, 公营 
Risk Analysis and Crisis Response in Big Data Era (RAC-16)

风景区损失约 6 亿元，全岛 $1 / 3$ 风景点受损， 连接全岛的干线公路中断, 南投、台中、花莲 等县旅游设施损毁严重。加之灾后, 媒体对震 情灾情的倾盆报道，全岛旅游顿时陷于一片停 滞, 境外旅游团取消达 9 成, 岛内旅游取消达 7 成, 出境旅游取消达 5 成, 航空公司取消预 订机位 21 万个, 旅游住宿下跌 6 成以上, 一 些宾馆饭店入住率仅有 1 成 ${ }^{[1]}$ 。旅游业是新奥 尔良的支柱产业之一, 当地的餐饮业和会展业 也十分发达, 2004 年新奥尔良接待游客 1010 万人次。新奥尔良风䢐风过后, 2005 年 9 月一 -2006 年 5 月有 450 个会议被取消, 仅此一 项损失高达 35 亿美元。当地旅馆业也遭受了 毁灭性的的打击, 全市原有旅馆 266 家, 风具风 过后重新开业的只有 24 家, 市区约 8.2 万套 客房对外开放的只有 1.3 万套。风㝵风过后的几 个月里, 新奥尔良的游客几乎绝迹, 2005 年 的游客量仅为 850 万人次 ${ }^{[2]}$ 。2008 年中国汶川 地震, 造成旅游业直接经济损失 600 亿元人民 币, 2008 年 5 月比 4 月减少人入境外国游客 24.95 万人次 (见表 1$)^{[3]}$ 。

进入 21 世纪以后, 中国旅游业的发展进 入了一个快速增长时期。在旅游业总体持续繁 荣的背景下, 一方面突发性灾害事件对旅游业 造成的部分地段或时段的 “局部衰退” 被淡化 了; 另一方面, 随着旅游业的快速发展, 游客 对于旅游的品质要求也不断提升, 但由于近年 来旅游灾害事件频发, 极大地影响了游客的观 光旅游意愿。

全球气候环境不断变化, 极端天气事件频 发, 在 IPCC 第四次评估报告指出, 在气候变
暖的影响下, 未来极端灾害事件 (热浪、暴雨、 干旱、台风强度增加、海平面升高) 发生的概 率将提高。在灾害与环境变迁之下, 灾害规模 不断的扩大, 灾害所造成的损失也随之剧增。 重大的伤亡容易发生在灾害的气候敏感区位, 如: 河川流域 (水土复合型灾害)、山区安全 (高脆弱度和环境敏感) 以及沿海与低洼地区 (高脆弱度和灾害风险)。自然风景区, 是以 自然旅游资源为主, 具有完备的旅游设施和旅 游接待能力, 能够吸引旅游者完成一系列旅游 活动的空间地域 ${ }^{[4]}$ 。旅游业者为了充分利用自 然资源多选择风景秀丽、临山面海的区域进行 建设, 因此自然风景区大多位于海滩、河谷和 山区等地区, 而相关区域也隐含着救灾资源贫 乏和灾害风险性高的特点。随着自然风景区观 光旅游业的快速发展, 大量的游客一方面将会 提升自然风景区灾害脆弱性, 另一方面将会降 低风景区减轻灾害风险的能力。并且, 当灾害 发生时, 游客常常成为一种 “当地社区的威 胁”。

面对自然风景区灾害风险管理的严峻挑 战, 并且为了与提升旅游品质, 如何大幅减少 灾害为风景区带来的损害? 如何兼顾旅游经 济发展与灾害防治工作, 成了目前极为重要且 迫切的工作。国内外很多灾害事件证明, 社区 的自主性救援, 能够缩短搜救时间从而提高受 灾群众的存活率。那么, 对于景区的游客而言, 如果他们能够获得正确的风险信息, 他们就可 以成为减轻自然风景区灾害风险的优势。综合 风险雷达可以提供游客简单明了的灾害风险 及防救灾信息。并且, 为了减少灾害发生或防

表 1. 国内外重大灾害事件对旅游业的影响

\begin{tabular}{|c|c|c|c|c|}
\hline 国别 & 灾害事件 & 年份 & $\begin{array}{l}\text { 旅游业直接经济损失 } \\
\text { (人民币元) }\end{array}$ & 灾害发生后游客接待量变化 \\
\hline 中国 & 冰雪灾害 & 2008 & 69.7 亿 & $\begin{array}{l}2008 \text { 年 } 2 \text { 月比 } 1 \text { 月减少入境外国游 } \\
\text { 客 } 31 \text { 万人次 }\end{array}$ \\
\hline 中国 & 汶川地震 & 2008 & 600 亿 & $\begin{array}{l}2008 \text { 年 } 5 \text { 月比 } 4 \text { 月减少人入境外国 } \\
\text { 游客 } 24.95 \text { 万人次 }\end{array}$ \\
\hline 泰国 & 印度洋海啸 & 2004 & 0.8 亿 & $\begin{array}{l}2005 \text { 年 } 1 \text { 月比 } 2004 \text { 年 } 12 \text { 月减少 } 40 \\
\text { 万人次 }\end{array}$ \\
\hline 美国 & 卡特里娜风县风 & 2005 & 808.8 亿（估算） & $\begin{array}{l}2006 \text { 年比 } 2005 \text { 年游客量减少 } 480 \\
\text { 万人次, 月均减少 } 40 \text { 万人次。 }\end{array}$ \\
\hline
\end{tabular}




\section{Risk Analysis and Crisis Response in Big Data Era (RAC-16)}

止灾害扩大，自然风景区可通过 “综合风险雷 达” 的应用进行防灾减灾规划、收容场所区位 适宜性分析、疏散避难线路规划而降低灾害所 带来的冲击。因此, 本研究旨在建立自然风景 区综合风险雷达模式, 以期为建立智慧防灾景 区, 实现景区防灾的智慧化提供参考。

\section{2. 国内外研究现状与分析}

\section{1 景区灾害研究现状}

由于景区暴露的复杂性、灾害的突发性以 及动力机制的模糊性, 景区灾害的相关研究集 中在景区对灾害的响应与恢复上, 对灾害风险 评价与管理的研究还相当缺乏。这类研究以企 业经营者和本地政府为对象, 针对危机发生时 和发生以后, 从应急策略和营销的角度, 探讨 应对方案和恢复方法 ${ }^{[-8]}$ 。虽然还有一些对旅 游灾害风险的研究, 但主要关注全球气候变化 的背景下致灾因子的角度, 如雪崩 ${ }^{[9]}$ 、降雨 ${ }^{[10]}$ 、 风暴 ${ }^{[11]}$ 。

直到近几年, 对景区灾害风险评价与管理 的研究才进入国外学者的视野, 由于景区风险 相关概念还比较新颖, 目前主要集中在管理机 制的研究和模型构建上。奥罗扬 (Oroian) 以 旅行社为对象, 通过实证研究提出建立景区风 险管理模型 ${ }^{[12]}$ 。蔡 (Tsai) 建立了旅游业面对 自然灾害的快速风险评估模型 ${ }^{[13]}$ 。由于地震对 旅游业和游客心理的重大威胁, 关于地震风险 管理的文章比较集中: 奥彻斯顿 (Orchiston) 以新西兰南岛基督城地震为例进行风险情景 分析, 讨论了景区可持续发展管理 ${ }^{[14]}$ 。蔡 (Tsai) 以地震为例研究了景区灾害风险管理 机制 ${ }^{[15]}$ 。

应该看到, 国内这些涉及与旅游风险相关 的安全、危机、灾害等问题的研究很多, 但能 上升到灾害风险层面的却不多。对于旅游地安 全的研究也主要集中在旅游灾害系统研究以 及旅游业危机管理应急管理、灾后救援及恢复 上, 对于旅游风险评价与管理研究刚刚起步且 零星分散。

\section{2 风险雷达研究现状}

风险雷达不是电磁雷达, 而是为了风险评 估和管理而收集、处理方方面面不同数据的一
个信息系统 ${ }^{[16]}$ 。目前, 多种各样的风险雷达已 装备商业。“安永风险宇宙” 被广泛使用。早 在 2005 年 10 月, 新加坡政府就着手建立风险 “雷达”, 以地平线扫描系统的方式, 察觉恐 怖分子和其它对国家安全的威胁。该系统收集 相关数据、智能化分析这些数据, 并帮助各部 门或机构用这些信息进行更好地合作。然而, 至今并未见到新加坡风险雷达的踪影。主要原 因可能是传统技术的集成支撑不了供国家使 用的风险雷达。

2013 年 5 月 23 日, 历时 5 年的欧盟第 七框架计划大型项目 iNTeg-Risk 结题, 发 布了“iNTeg-R isk 宣言”, 呼吁建立 “欧洲 新兴风险雷达”, 确保实现在 2020 年将欧洲 生产事故降低 $25 \%$ 的目标。这里, 风险雷达 被定义为对风险进行监测的工具。基本功能 是, 根据社会、政治、经济、金融、监管、法 律和技术等因素确定的关键性问题, 对相关风 险进行动态识别、定位和评估。与传统风险雷 达概念不同的是, 这种风险雷达是为多用户打 造的, 每个人都可以有自己的 “翻译” 结果 ${ }^{[16]}$ 。

银行、商业用的风险雷达, 属于静态风险 分析。并且, 今天的风险雷达, 主要的功能是 显示, 类似于风险矩阵。随着社会和经济的快 速发展, 灾害风险事件的风险水平呈现出明显 的动态变化性特点。黄崇福 ${ }^{[17-18]}$ 、吴粀 ${ }^{[19]}$ 等提 出了智联网驱动的风险雷达, 以智联网作为风 险的动态变化监测追踪驱动平台并将结果以 风险雷达展示的在线风险分析及展示表达工 具。

\section{3 国内外研究分析}

20 世纪 90 年代由于景区受到灾害威胁问 题不断增加, 景区灾害问题引起了广泛的社会 关注, 掀起了景区灾害风险研究的小高潮。通 过对国内外景区灾害管理的相关文献的分析, 可以看出, 研究的内容从景区灾害的应对策 略、灾害的影响研究扩展到灾害的风险评价与 风险管理等内容。但是也存在一些尚未解决的 问题。例如, 不同类型的灾害对不要地域不同 类型的景区旅游者的时空特性的影响机理是 否相同, 需要我们研究。另外, 近年来风险地 图已成为灾害风险管理中迅速崛起的新领域, 但在景区灾害风险研究尚未被关注, 并且全球 
Risk Analysis and Crisis Response in Big Data Era (RAC-16)

的大多数灾害风险图并没有时效性。以此为依 据的风险管理, 常使人们处于被动的 “应对” 地位。以智联网为驱动的在线风险雷达为我们 提供了一个研究景区动态风险与建立智慧防 灾景区的新思路。

\section{3. 防灾景区与智慧防灾的定义}

\section{1 防灾景区}

景区内的每一个游客都希望处在一个零 风险零灾害的安全、舒适的旅游环境中, 防灾 景区的目标就是要建立一个具有备灾与防灾 减灾意识的景区。简单来说, 防灾景区应该要 具备:

(1) 有能力降低灾害发生的机会(减灾)。

（2）能够承受灾害冲击, 并能立即应变, 降低灾害损失 (备灾、应变)。

(3) 可以在灾后迅速复原重建, 并持续 地发展 (重建)。

当景区本身具有强有力的灾害风险意识, 而且能够自动自发地进行, 从平时、灾时到灾 后的各项防救灾工作……, 就可以被称为 “自 主防灾景区”。

\section{2 智慧防灾}

智慧防灾: 通过云端运算、物联网、巨量 资料分析等技术的结合, 将传感器嵌入和装备 到风景区每个角落的供电系统、供水系统、交 通系统、建筑物等, 从而为建立智慧防灾景区, 即通过云端模式打造景区灾害监测物联网 (图 1), 让景区管理人员以最快的速度启动防灾、 救灾机制, 实现风景区防灾的智慧化。

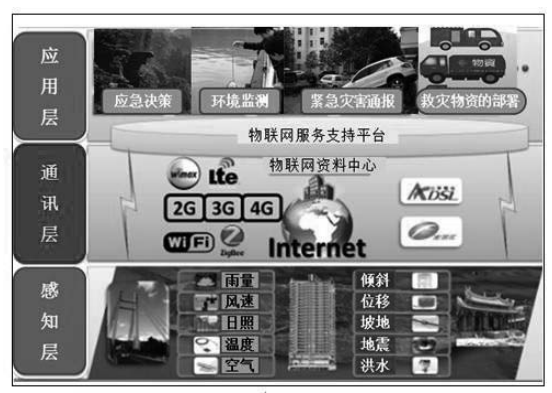

图 1. 景区灾害物联网技术架构图

\section{4. 基于物联网的景区综合风险雷达的模式}

\section{1 综合风险雷达的模式}

发现、识别、监测和管理动态风险的系统, 称为风险雷达。景区综合风险雷达采用面向服 务的体系架构, 面向景区游客提供景区灾害隐 患资料的录入维护服务和地理信息服务。图 2 为景区综合风险雷达运作机制, 景区主管部门 先利用专业 GIS 软件叠加所需图层资料 (包括 基础地理信息数据和灾害应急相关数据) 制作 景区的电子风险地图, 然后开发一款手机 APP, 游客可以通过手机 APP 将在现场发现的灾害 隐患直接在电子风险图上标注点位坐标或相 关信息, 这样可即时将信息反馈给总部, 达到 数据更新的目的。

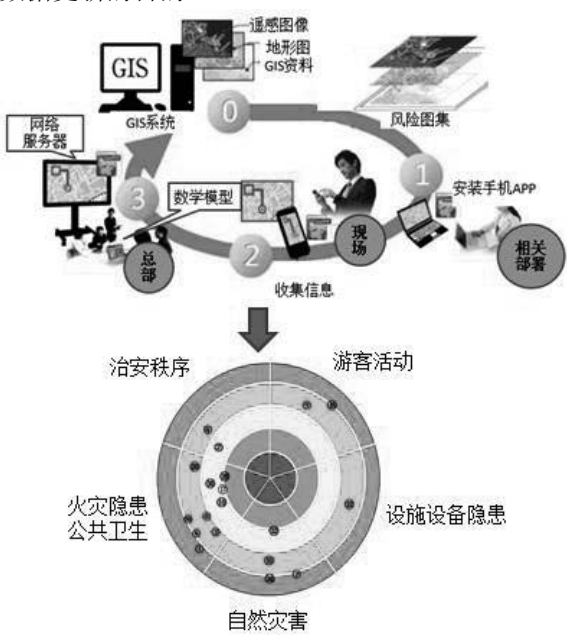

图 2. 景区综合风险雷达运作机制

景区综合风险雷达主要具备三个功能模 块 (图 3):

(1) 隐患排查

游客通过手机 APP 将在现场发现的灾害 隐患资料直接在电子风险图上标注点位坐标 或相关信息, 这样可即时将信息反馈给总部, 然后总部派遣现场执勤人员进行隐患点的实 地勘察。通过游客反馈的巨量监测数据管理及 分析功能, 提供管理决策者即时的数据分析, 及相关环境风险预警状况, 包括找出灾害预测 模式, 提供系统化、科学化的防灾管理基础信 息。 


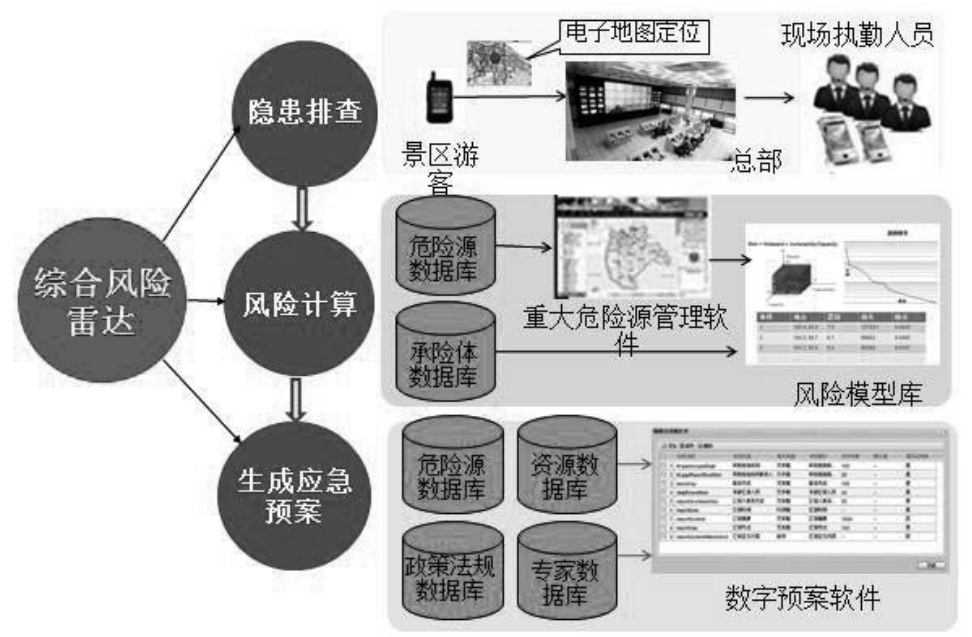

图 3 景区综合风险雷达功能模块

（2）风险计算: 风险后果 $\times$ 可能性

综合风险雷达系统将根据需求设计出一 套景区灾害风险评估计算系统, 实现风险评估 的计算自动化。

(3) 应急预案的自动生成。

综合风险雷达的目标就是协助景区决策 者收集、统计、分析各种监测数据, 提供人工 智慧、专家系统功能, 协助防灾决策人员在最 短的时间做出最正确的应急判断。因此, 综合 风险雷达的第三个功能是根据计算的风险信 息, 组织人员、准备器材, 自动生成应急预案。

\section{2 景区综合风险雷达的应用情景分析}

\subsection{1 环境全面监测}

通过景区综合风险雷达, 可以全面掌握景 区中雨量、河流水位、坡地、道路、空气质量、 水质等环境指标的即时信息。

\section{2.2 灾害应急决策}

建立专家决策系统, 进行各式灾害数据分 析, 让景区决策者得以快速地采取应急措施, 加快决策与应急的时效。

\section{2.3 紧急灾害通报}

提供即时、高效的紧急灾害通报机制, 景 区决策者可以用短信、广播等手段通知游客, 进行避难及疏散。

\subsection{4 救灾物资的部署}

发生大型灾害后，提供景区的影像资料、 通讯联系机制, 让救灾物资得以快速运送及部 署, 选择合适的物资调派路线, 让物资能在最 短的时间内送到受灾游客手中。

\section{5. 结论}

全球气候环境不断变化, 极端天气事件频 发, 并且游客越来越关注旅游的品质与安全, 因此, 自然风景区灾害风险管理面临着严峻挑 战, 也对景区的综合防灾体系提出了更高的要 求。智慧技术的飞速发展, 又为景区防灾的“智 慧化” 提出了新的要求。

随着自然和社会的变化, 自然风景区的灾 害风险必然发生变化。变化着的风险称为动态 风险。发现、识别、监测和管理动态风险的系 统, 称为风险雷达。为了提升景区的旅游品质 与安全, 实现景区综合防灾体系的 “智慧化”, 优化提升景区综合防灾体系的运作效果, 本文 提出的景区综合风险雷达模式, 目前还只是一 个新的概念模式, 还没有大规模实施, 也没有 产业化基础。因此, 要实现大范围、大规模的 向智慧防灾景区发展, 今后还将与课题组展开 深入的研究, 推动关键技术的研发、应用示范 与推广。 
致谢

本项目由国家自然科学基金项目 (No. 41071327 ) 和黄山学院 2012 年度校级科 研项目（No. 2012xkjq005）资助。

\section{参考文献}

[1] 高舜礼,白四座,韩玉灵. 台湾旅游业 “9.21”大地震灾后振兴的启示. http://finance.sina.com.cn/g/20081006/0046 5356022.shtml,2008-10-06.

[2] 郭剑英.中外大灾害对旅游业的影响及对 四川旅游业恢复的启示. 资源开发与市 场,2009,25(4):349-352.

[3] 勾佳.突发性自然灾害对目的地旅游业的 影响研究一以汶川地震为例. 重庆师范大 学,2012.

[4] 张雪梅. 自然风景区开发中的若干问题研 究—以河北省为例.河北师范大学,2008.

[5] 叶欣梁.旅游地自然灾害风险评价研究— 以九寨沟为例.上海师范大学, 2011 .

[6] L. Barton. Crisis management: preparing for and managing disaster. The Hotel and Restaurant Administration Quarterly, 1994, 35(3): 59-65.

[7] T. Drabek. Disaster responses within the tourist industry. International Journal of Mass Emergencies and Disasters, 1995, (13): 7-23.

[8] B. Ritchie. Tourism disaster planning and management: from response and recovery to reduction and readiness. Current Issues in Tourism, 2008, 11(5):315-348.

[9] D. O'Gorman. Parks Canada's Backcountry Avalanche Risk Review. Ottawa: Independent Panel for Parks Canada, 2003. 16.

[10] G.M. Ma Belén. Weather, climate and tourism a geographical perspective. Annals of Tourism Research, 2005, 32(3): 571-591.

[11] K. Méheux, E. Parker. Tourist sector perceptions of natural hazards in Vanuatu and the implications for a small island developing state. Tourism Management, 2006, 27(1): 69-85.
[12] M. Oroian, M. Gheres. Developing a risk management model in travel agencies activity: An empirical analysis. Tourism Management, 2012, 33(6): 1598-1603.

[13] C. Tsai, C. Chen. The establishment of a rapid natural disaster risk assessment model for the tourism industry. Tourism Management, 2011, 32(1), 158-171.

[14] C. Orchiston. Seismic risk scenario planning and sustainable tourism management: Christchurch and the Alpine Fault zone, South Island, New Zealand. Journal of Sustainable Tourism, 2012, 20(1): 59-79.

[15] C. Tsai, C. Chen. An earthquake disaster management mechanism based on risk assessment information for the tourism industry: A case study from the island of Taiwan. Tourism Management, 2010, 31(4): 470-481.

[16] 黄崇福.自然灾害动态分析分析基本原理 的探讨.灾害学,2015,30(2):1-7.

[17] C.F. Huang, T. Wu, O. Renn. A Risk Radar driven by Internet of intelligences serving for emergency. Environmental Research, 2016, 148:550- 559.

[18] C.F. Huang. Internet of intelligences in risk analysis for online services. Journal of Risk Analysis and Crisis Response, 2011, 1(2):110-117.

[19] 吴娅, 艾福利, 郑建军, 黄崇福. 智联网 驱动的风险雷达实现探讨. 风险分析和 危机反应中的信息技术, 黄崇福, 包玉 海, 赵思健编. 巴黎: Atlantis 出版社, pp. 468-472, 2014. 